\title{
«УМНЫЙ ГОРОД»: ОЦЕНКА ПОКАЗАТЕЛЕЙ КАЧЕСТВА ЖИЗНИ НА ОСНОВЕ ЦИФРОВОГО СЛЕДА
}

\author{
Курчеева Галина Ивановна \\ к.э.н., доцент
}

Новосибирский государственный технический университет

Бабайкина Елизавета Юрьевна

Новосибирский государственный технический университет

Аннотация: С ростом темпов урбанизации все более актуальной становится концепция городского развития «Умный город». Концепция «Умный город» направлена на повышение качества жизни населения за счет цифровизации различных сфер жизнедеятельности города. Существует потребность в создании методологии оценки качества жизни населения, которая позволяла бы учитывать множество компонентов общественной жизни, которые отражают реальные условия жизни людей. Анализ геолоцированных цифровых следов, собранных через ГИС или социальные сети, позволяет приблизиться к созданию более комфортной городской среды.

Ключевые слова: Цифровой след, умный город, показатели качества жизни.

\section{SMART CITY: ASSESSMENT OF QUALITY-OF-LIFE INDICATORS BASED ON DIGITAL FOOTPRINT}


Abstract: With the increasing pace of urbanization, the concept of urban development "Smart City" is becoming more and more relevant. The concept of "Smart City" is aimed at improving the quality of life of the population through digitalization of various spheres of the city's life. There is a need to create a methodology for assessing the quality of life of the population, which would allow taking into account many components of public life that reflect the real living conditions of people. The analysis of geolocated digital traces collected through GIS or social networks allows us to get closer to creating a more comfortable urban environment.

Key word: Digital footprint, smart city, quality of life indicators.

\section{Введение}

С каждым годом в мире увеличивается количество городских жителей на сегодняшний день больше половины населения Земли проживает в городах. Переезжая в крупные города, люди стремятся к большим возможностям и лучшему качеству жизни. Но насколько комфортна жизнь в мегаполисе сегодня? Городские жители постоянно сталкиваются с рядом проблем, к которым относятся недостаточно развитая инфраструктура городов, частые пробки на дорогах, загрязненность окружающей среды, недостаточное количество зеленых насаждений и многие другие.

С ростом темпов урбанизации все более актуальной становится концепция городского развития «Умный город». Понятие «Умный город» (Smart City) не имеет единственного четкого определения, поскольку эта концепция объединяет в себе множество факторов. Например, Европейская экономическая комиссия ООН определяет умный город, как «инновационный город, использующий информационно-коммуникационные технологии и другие средства для повышения уровня жизни, эффективности деятельности и услуг в городах, а также конкурентоспособности при обеспечении 
удовлетворения потребностей настоящего и будущих поколений в экономических, социальных, культурных и природоохранных аспектах» [1]. Международная консалтинговая компания McKinsey \& Company в одном из своих ежегодных отчетов определяет современный умный город, как «место, где жизнь человека обретает новое качество благодаря использованию технологий и цифровизации традиционных услуг» [2]. Концепция умного города также развивается и в России. Далее приведем определение, сформулированное Министерством строительства и жилищно-коммунального хозяйства РФ (Минстрой России): «Умный город - это проект, который направлен на повышение конкурентоспособности российских городов, формирование эффективной системы управления городским хозяйством и создание безопасных и комфортных условий для жизни горожан. Он базируется на 5 ключевых принципах: ориентация на человека; технологичность городской инфраструктуры; повышение качества управления городскими ресурсами; комфортная и безопасная среда; акцент на экономической эффективности, в том числе, сервисной составляющей городской среды» [3].

Во многих работах, как, например, в [4] авторы выделяют шесть основных сфер умного города: умная экономика; умные люди; умное управление; умная мобильность; умная среда; умная жизнь (высокое качество жизни и т. д.).

В современных работах, например, в [5] рассматривается четыре измерения умного города: управление городом (сотрудничество между различными заинтересованными сторонами, которые активно участвуют в коллективном процессе принятия решений); социально-институциональная структура; технико-экономическая структура (человеческий капитал); городская среда (мобильность, дизайн города, удобство и природная среда). 
Таким образом, можно сделать обобщающий вывод о том, что мероприятия концепции «Умный город» направлены на повышение качества жизни населения за счет цифровизации различных сфер жизнедеятельности города.

Качество жизни населения в концепции умного города

В настоящее время понятие «качество жизни» широко используется в различных нормативных документах и проектах. Поскольку данное понятие является достаточно размытым, приведем несколько вариантов его определений. Всемирная организация здравоохранения (ВОЗ) определяет качество жизни как восприятие человеком своего положения в жизни в контексте культуры и системы ценностей, а также по отношению к своим целям, ожиданиям, стандартам и переживаниям [6]. Ученые приводят следующее определение: «качество жизни - это совокупность параметров, отражающих измерение течения жизнедеятельности с оценкой физического состояния, психологического благополучия, социальных отношений и функциональных способностей» [7]. Международные организации по основным показателям экономической деятельности и социального прогресса определяют следующие составляющие оценки качества жизни человека [8]: материальное потребление товаров и услуг; здоровье; образование; доступ к интересной работе, хобби и другие виды деятельности; участие в политической деятельности и управлении; социальные связи и участие в жизни своего социального окружения; экология среды обитания; физическая безопасность, гарантии трудоустройства и дохода.

Таким образом, многообразие сфер, затрагиваемых в определении понятия «качество жизни» позволяет говорить о качестве жизни как об оптимальном сочетании параметров здоровья, досуга, занятости, образования, профессионального и социального роста, защищенности прав и свобод, безопасности и чистоты окружающей среды. 
В инфраструктуре умного города объединено множество различных технологий и систем, что приводит к таким эффектам, как возможность получения актуальной информации о городской инфраструктуре и сбора большого количества данных, которые в дальнейшем можно использовать для анализа в целях повышения уровня качества жизни населения. Для обеспечения слаженной работы большого количества не всегда связанных между собою городских систем во многих странах мира разрабатываются, как национальные, так и международные стандарты умного города. В работе [9] был проведен сравнительный анализ стандартов и критериев умного города различных стран и организаций. Среди рассмотренных документов были стандарт международной организации по стандартизации (ISO), стандарты Британского института стандартизации (BSI), критерии программы Smart Cities Mission (Индия), критерии MCЭ и Европейской экономической комиссии ООН, а также стандарт Минстроя России. Анализ показал, что во всех перечисленных выше документах наиболее приоритетными являются такие сферы умного города, как телекоммуникации и экология.

Стоит понимать, что основной целью умного города является не развитие инфокоммуникационных технологий, а способствование благополучию и сохранению здоровья жителей с использованием этих самых технологий. Согласно отчету компании McKinsey [10], использование в городе «умных» технологий может привести к значению прироста по различным индикаторам качества жизни от 10 до 30\%. Таким образом, информационные технологии являются лишь инструментом для оптимизации ресурсов и городского пространства, а основной целью создания умного города является повышение качества жизни населения и создание более удобных для проживания городов. 


\section{Показатели качества жизни населения и их измерение.}

В связи с тем, что оценка качества жизни и благополучия является основной целью концепции «Умный город», она представляет огромный теоретический и практический интерес как для научных исследований, так и для органов управления. Таким образом, существует острая потребность в создании методологии оценки качества жизни населения, которая позволяла бы, с одной стороны, учитывать множество компонентов общественной жизни, которые отражают реальные условия жизни людей, а с другой реализацию такого измерения можно было осуществлять оперативно и на регулярной основе для оптимального сопровождения управленческих решений. Рассмотрим и проанализируем некоторые существующие на сегодняшний день общемировые практики оценки качества жизни населения.

1. Система национальных счетов [11] представляет собой систему взаимосвязанных показателей и классификаций, включающую в себя чистый национальный доход, ВВП (внутренний валовый продукт), ВНП (валовый национальный продукт), личный и располагаемый личный доходы населения. Используя методику оценки качества жизни, основанную на такой системе, можно изучить формирование расходов и доходов, а также измерить не только личный доход населения, но и тенденции экономического развития регионов. Недостатком системы национальных счетов является то, что в ней используются лишь экономические показатели общественной жизни.

2. Индекс развития человеческого потенциала ООН (Human Development Index HDI) [12] публикуется в ежегодных отчётах о развитии человеческого потенциала с 1990 года. С помощью методологии HDI можно оценить такие показатели, как ожидаемая продолжительность жизни, уровень грамотности населения страны и уровень жизни, оценённый через валовый национальный доход на душу населения по паритету покупательной способности (ППС) в долларах США. В соответствии с данной методологией 
выделяется четыре группы стран: с очень высоким, высоким, средним и низким уровнем HDI.

3. Глобальный индекс благополучия Gallup-Healthways (GallupHealthways Global Well-being Index) [13] включает в себя пять основных аспектов благополучия жизни:

- физический (хорошее здоровье и достаточный запас энергии для осуществления ежедневной работы);

- социальный (наличие поддержки и любви);

- финансовый (управление экономической ситуацией, нацеленное на снижения стресса и повышение безопасности);

- общественный (ощущение безопасности и гордость за принадлежность к обществу);

- успех (взаимосвязь между каждодневными делами и мотивацией для достижения целей).

Методика предполагает исследование на основе общественных опросов, на основе которого участники распределяются на три категории внутри каждого аспекта благополучия: «процветает» (хорошее качество жизни), «борется» (среднее качество жизни), «страдает» (плохое качество жизни). В каждой стране рассчитывается доля жителей, принадлежащих к каждой из категории, после чего все страны разбиваются на группы в соответствии с долей «процветающих» по трем или более аспектам благополучия.

1. Индекс качества жизни от британской компании Economist Intelligence Unit [14] был разработан в 2002 году на основании следующих индикаторов качества жизни:

- материальное благосостояние (ВВП на душу населения долларах США);

- здоровье (ожидаемая продолжительность жизни при рождении) 
- политическая стабильность и безопасность, основанные на рейтингах;

- семейная жизнь (коэффициент разводов на 1000 человек населения, пересчитанный в индекс от самого низкого (1) до самого высокого (5) уровня разводов)

- общественная жизнь (1, страна имеет высокий уровень посещаемости церкви или членства в профсоюзах, в противном случае - 0);

- климат и география (теплый или холодный климат);

- гарантия занятости (уровень безработицы в стране);

- политическая свобода (среднее значение показателей политических и гражданских свобод в значении от 1 (совершенно свободная страна) до 7 (несвободная));

- равенство полов (соотношение среднего заработка мужчин и женщин).

2. Всемирный индекс счастья (Happy Planet Index (HPI)) был разработан британским исследовательским центром Фонд новой экономики (New Economics Foundation (NEF)) совместно с рядом экологических НКО и группой независимых международных экспертов [15]. Индекс HРI отражает благосостояние людей и состояние окружающей среды в разных странах мира. Основными показателями индекса являются ожидаемая продолжительность жизни (ОПЖ), опыт благополучия (ОБ) и экологический след (ЭС). Сам индекс рассчитывается по следующей формуле:

$$
H P I=\frac{\text { ОБ } * \text { ОПЖ }}{Э С}
$$

Итоговый индекс счастья изменяется в пределах от 1 до 100, при этом чем выше индекс, тем больше счастья. В соответствии с индексом страны делятся на 6 групп: 1. все три показателя индекса хорошие; 2. два показателя хорошие, один средний; 3. один показатель хороший, два средние; 4. три 
показателя средние; 5. один из показателей плохой; 6. два плохих показателя или один показатель очень плохой.

Таким образом, можно увидеть, что существует большое количество различных подходов к измерению качества жизни населения. Каждый из них обладает своей методикой расчета, которая содержит те или иные показатели. При этом практически все индексы качества жизни учитывают такие факторы, как экономическое благополучие граждан, их безопасность, здоровье, общественная жизнь и многие другие.

Влияние зеленых насаждений на качество жизни населения

Рассмотренные ранее системы оценки качества жизни населения имеют много общих составляющих. Очевидно, что такой фактор, как здоровье является основополагающим в оценке качества жизни населения. Это подтверждают и индексы HDI и HPI, учитывающие продолжительность жизни населения, и индекс Gallup-Healthways, одним из компонентов которого является физический аспект, и индекс EIU, содержащий индикатор здоровья. Для подавляющего большинства населения планеты, проживающего в городах, очень важно находиться в окружающей среде, которая способствует укреплению здоровья.

Жизнь в городе ограничивает доступ его жителей к природе, а также увеличивает их подверженность вредным факторам окружающей среды, таких как загрязнение воздуха, большое количество пыли на дорогах и т.д. Парки, скверы, игровые площадки, а также зеленые насаждения в общественных и частных зонах могут создать для городских жителей адекватные возможности для контакта с природой.

Факты, свидетельствующие о связи между наличием зеленых зон и здоровьем населения, были сформулированы во многих публикациях. Например, в работе [16] было сформулировано четыре основных способа, посредством которых городские зеленые зоны могут влиять на здоровье и 
благополучие жителей. К ним относятся, улучшение качества воздуха, повышение физической активности, снятие стресса и большая социальная сплоченность. В отчете Европейского регионального бюро ВОЗ [17] были рассмотрены эпидемиологические исследования, которые продемонстрировали положительные эффекты от городских зеленых насаждений, такие как снижение количества депрессий и улучшение психического здоровья, уменьшение уровня сердечно-сосудистой заболеваемости и смертности, улучшение исходов беременности, а также снижение показателей ожирения и сахарного диабета.

Положительное влияние физической активности на здоровье зависит от наличия общественных зеленых насаждений, подходящих для активного отдыха. При этом существует и определенная связь между наличием зеленых насаждений в непосредственной близости от места проживания и пользой для здоровья. Это говорит о том, что пребывание в зеленой зоне может принести пользу здоровью независимо от уровня физической активности [18]. Таким образом, на повышение качества жизни населения оказывают влияние не только парковые зоны, но и общий уровень озеленения жилых районов.

В руководстве Европейского регионального бюро ВОЗ, содержащем практические рекомендации по озеленению городов [19], подчеркивается, что «городские зеленые зоны являются одним из компонентов озеленения городов или «зеленой инфраструктуры», поэтому необходимо обеспечить, чтобы общественные зеленые зоны были легкодоступны для всех групп населения и справедливо распределялись внутри города».

В 2015 году Генеральной ассамблеей ООН был разработан набор из семнадцати взаимосвязанных целей, которые образовали документ, названный «Повесткой дня в области устойчивого развития на период до 2030 года». Под устойчивым развитием в нем подразумевается принятие мер, направленных на оптимальное использование ограниченных ресурсов, а также использование 
экологичных технологий, сберегающих природные, энергетические и материальные ресурсы. Одной из представленных в документе целей является «Обеспечение открытости, безопасности, жизнестойкости и экологической устойчивости городов и населенных пунктов» [20]. Среди задач, поставленных для достижения этой цели, можно выделить обеспечение к 2030 году всеобщего доступа к безопасным, доступным, открытым для всех зеленым зонам и общественным местам, особенно для женщин и детей, пожилых людей и инвалидов, а также уменьшение негативного экологического воздействия городов в пересчете на душу населения.

Основные усилия по обеспечению устойчивого развития, чаще всего направлены на понимание и управление факторами, которые влияют на все аспекты здоровья и благополучия населения. Многие исследования показали, что общественные парки и зеленые насаждения предоставляют городским жителям различные физические, психологические и социальные положительные аспекты. При этом не так много исследований было посвящено изучению влияния парков на комплексные показатели субъективного благополучия на городском уровне.

Используя данные за 2014 год из 44 городов США, в исследовании [21] была проведена оценка взаимосвязи между количеством, качеством и доступностью городских парков, а также собранными показателями самопроверки индекса благополучия Gallup-Healthways (WBI), который учитывает пять различных областей благополучия (физическое, социальное, финансовое благополучие, принадлежность к сообществу и успешность). Результаты корреляционно-регрессионного анализа, проведенного в данном исследовании, показали, что процент парковых зон в каждом городе значительно связан с общим благополучием на городском уровне. Положительное влияние было выявлено практически по всем шкалам индекса благополучия WBI - физической, финансовой, социальной и 
общественной. Единственная наблюдаемая отрицательная связь была между доступностью парка (процент населения, проживающего в близости с парками) и шкалой успеха.

Освещение городских парков также оказывает положительное влияние на благополучие общества и чувство вовлеченности людей в место, где они живут. Парки и скверы предоставляют уникальную форму социального места для встреч в густонаселенных городах и облегчает социальное взаимодействие и сотрудничество, а также способствует чувству привязанности к сообществу. Таким образом, зеленые зоны могут способствовать созданию социального капитала и последующему повышению благополучия сообщества, которое является определяющим фактором многих устойчивых городских сообществ.

Городской цифровой след и методы его сбора

В жизнь в современном городе все больше внедряются различные цифровые сервисы и приложения. В результате большого количества действий, которые городские жители ежедневно совершают с помощью своих смартфонов, возникают большие объемы «цифровых следов», вплетенных в ткань материального города при помощи геолокации, выступающей в роли своего рода общего знаменателя.

В работе Тома Белстроффа [22] большие городские данные разделяются на два типа: «условно неуправляемые» и «условно управляемые». Под управляемостью в данных терминах понимается наличие у пользователя намерения опубликовать свои «следы» онлайн. Таким образом, условно управляемыми можно считать, прежде всего, данные из социальных сетей и блогов, а условно неуправляемыми - например, данные мобильных операторов, следов банковских транзакций, маршрутов в спортивных приложениях, кукисов загруженных нами веб-страниц и т.д. 
При этом данные и той, и другой категории являются дискретными люди публикуют лишь выборочную информацию в социальных сетях, и при этом не все социальные сети предоставляют открытие API, и не все пользователи делают свои аккаунты публичными, а данные мобильных операторов зависят от частоты сигнала и площади покрытия. С этим могут быть связаны различные проблемы при сборе и анализе городских цифровых данных.

Открытыми данными называется информация, которую собирают и публикуют государственные органы в форматах, подходящих для автоматической обработки без предварительного изменения человеком. Основная идея открытых данных заключается в их свободном доступе: все желающие могут использовать и распространять эти данные без ограничений, накладываемых авторскими правами, патентами и другими механизмами контроля. Открытые данные могут быть пространственными, т.е. содержать координатные данные. Такие геоданные могут быть широко использованы в проведении городских исследований и помочь найти ответы на такие вопросы, как «Соблюдены ли в районе нормы по зелёным насаждениям?», «Обеспечены ли жилые дома школами?», «Есть ли поблизости достопримечательности?», «Где есть проблемы с пешеходной доступностью?». Сервисы, являющиеся источниками геоданных, такие как, например, OpenStreetMap или созданный на его основе в университете ИТМО сервис YourMaps.io [23], могут помочь автоматизировать и упростить получение ГИС данных для проведения исследований. Использование платформ для проведения геопривязанных опросов, например, Mapsurvey, может позволить получить мнение пользователя о процессах и объектах окружающей среды.

Геолоцированные цифровые следы могут стать хорошим материалом для изучения городской среды. В основном, такие исследования направлены 
на оценку туристической активности городов - посещаемость определенных мест можно легко отследить с помощью анализа чекинов и опубликованных фотографий. Помимо этого, геолоцированные цифровые следы могут быть использованы и для оценки качества городских пространств. В работе [24] был предложен подход, в основе которого лежит следующая мысль: число фотографий определенных мест отражает «урбаничность» района, т. е. сочетание его эстетических характеристик и возможностей по предоставлению услуг. Урбаничность может быть характерна для городских пространств, содержащих природные рекреационные зоны, архитектурные достопримечательности, учреждения культуры и т.д. Данный подход подразумевает, что чем более привлекательно для горожан место, тем чаще они его фотографируют и выкладывают в Интернет.

Для изучения городских цифровых следов используются методы анализа данных. После сбора данные очищаются от рекламы и повторных записей, после чего они размечаются по ряду критериев: место и время создания фотографии, кто и что изображено на ней и т.д. Далее размеченные данные с геотегами накладываются на карту города [255]. Для того, чтобы понять какие городские пространства предпочитают молодые пользователи, был проведен анализ на основе цифровых следов. В результате была создана карта, на которой было видно количество фотографий, сделанных в разных частях города. Благодаря цифровым следам стало наглядно видно, какие зеленые зоны воспринимаются жителями наиболее позитивно.

Таким образом, в современном мире городские цифровые следы могут стать инструментом для создания комфортной городской среды и повышения качества жизни населения.

Повышение качества жизни населения по направлению «экология» на основе сбора цифрового следа 
Как правило, для изучения качества жизни и благополучия населения используются данные, полученные с помощью традиционных социологических исследований. В настоящее время благодаря цифровизации и развитию информационно-коммуникационных технологий появляются все новые возможности для изучения данной сферы. В последнее десятилетие сложилось целое направление исследований - цифровая социология, для которой характерно активное использование «цифровых методов», т. е. различных информационно-коммуникативных технологий для изучения социальных процессов и явлений. Цифровые методы социологических исследований также применяются в исследованиях благополучия и качества жизни населения. При этом, зачастую источником данных в изучении благополучия и качества жизни населения цифровыми методами являются цифровые следы пользователей.

Как было сказано ранее, повысить качество жизни населения можно за счет создания более комфортной городской среды. Проект «Умный город» может стать одним из инструментов повышения привлекательности территорий.

Повысить качество жизни населения по показателю «экология» можно путем учета мнения городских жителей и эффективного планирования размещения зеленых насаждений. Если расположение зеленых зон будет отвечать требованиям и пожеланиям жителей, то они будут более посещаемыми, и тем самым, потенциально могут принести больше пользы городскому населению. Сбор цифрового следа может помочь в учете мнения горожан. Данные, собранные с помощью городских информационных систем (ГИС) могут указать на места, в которых жители чаще всего бывают. Сбор таких данных может способствовать более эффективной оценке посещаемости мест, чем анализ социологических исследований, которые дают более субъективные данные. 
Повышению уровня жизни населения также может способствовать грамотный анализ уже проведенных работ с целью выявления достоинств и недостатков. Такой анализ можно провести на основе оценки успешности уже проведенных работ по благоустройству зеленых зон. Для того, чтобы оценить успешность проведения благоустройства городских пространств, необходимо собрать мнение жителей и проанализировать, как оно изменилось. Как правило, для этого используются различные анкетирования и опросы, в которых горожанам предлагается ответить на вопросы о том, насколько им нравится недавно благоустроенная территория. Намного более эффективным методом оценки отношения городских жителей является анализ изменения их поведения на благоустроенной территории - насколько чаще они стали посещать это место, насколько больше времени стали там проводить и т. д. Это можно проследить путем проведения наблюдений в исследуемых местах в течение определенного периода до начала проведения работ по благоустройству и такого же периода после их завершения.

Для проведения подобных исследований, посвященных анализу эффективности благоустройства, используются методы цифровой антропологии, а именно изучение геолоцированных цифровых следов практик пользования городом.

\section{Заключение}

Таким образом, анализ геолоцированных цифровых следов, собранных через ГИС или социальные сети, позволяет приблизиться к созданию более комфортной городской среды и, следовательно, повысить качество жизни населения. В частности, этого можно добиться в сфере экологии, которая определена как одна из приоритетных в концепции развития «умного города». Использование пространственных данных и геолоцированных цифровых следов также может позволить оценивать качество жизни населения на основе специально разработанных показателей. Цифровые следы, оставленные в 
городской среде, могут отражать общественное мнение горожан и указывать на посещаемость тех или иных мест. На основе цифрового следа можно также оценить результаты проведенного благоустройства и его влияние на уровень качества жизни населения. В результате применения методики мониторинга показателей качества жизни населения с использованием цифрового следа планируется получить рассчитанные значения индикаторов качества жизни, позволяющие проводить оперативный мониторинг городской среды для создания сценария последующих управленческих действий.

\section{Список литературы}

1. Показатели «умных» устойчивых городов, разработанные ЕЭК ООН-МСЭ / Европейская экономическая комиссия ООН UNECE, 2015 Режим доступа: https://www.unece.org/fileadmin/DAM/hlm/documents/ 2015/ECE_HBP_2015_4.ru.pdf

2. Джонатан Вотцель, Елена Кузнецова. Технологии умных городов: что влияет на выбор горожан? / McKinsey Center for Government, 2018 Режим доступа: https://www.mckinsey.com/ /media/McKinsey/Indust ries/Pub lic\%20and\% 20Social\%20Sector/Our\%20Insights/Smart\% 20city\%20 solu tions $\% 20$ What $\% 20$ drives $\% 20$ citizen $\% 20$ adoption $\% 20$ around $\% 20$ the $\% 20$ glo be/smartci tizenbook-rus.pdf

3. Проект цифровизации городского хозяйства «Умный город» / Минстрой России, 2020 - Режим доступа: https://minstroyrf.gov.ru/ trades/gorodskaya-sreda/proekt-tsifrovizatsii-gorodskogo-khozyaystva-umnyygorod/

4. Giffinger R., Gudrun H. Smart cities ranking: an effective instrument for the positioning of the cities? //ACE: architecture, city and environment. -2010 . $-\mathrm{T}$. 4. - №. 12. - C. 7-26. 
5. Camboim G. F., Zawislak P. A., Pufal N. A. Driving elements to make cities smarter: Evidences from European projects //Technological Forecasting and Social Change. - 2019. - T. 142. - C. 154-167.

6. WHOQOL: Measuring Quality of Life. URL: https://www.who. int/tools/whoqol

7. Учебное пособие / Под ред. д-ра экон. наук, профессора И.Г. Окрепиловой. - СПб.: Изд-во СПбГУЭФ, 2010. - 104 с.

8. Report by the Stiglitz Commission on the Measurement of Economic Performance and Social Progress [Электронный ресурс] Режим доступа: URL: https://www.researchgate.net/publication/258260767_Report_of_the_Commission_ on_the_Measurement_of_Economic_Performance_and_Social_Progress_CMEPSP

9. Макаренко К. В., Логиновская В. О. «Умный город»: стандарты, проблемы, перспективы развития //Вестник Южно-Уральского государственного университета. Серия: Компьютерные технологии, управление, радиоэлектроника. - 2019. - Т. 19. - №. 3.

10. McKinsey Global Institute Smart Cities: Digital Solutions for a More Livable Future June 2018. URL: https://www.mckinsey.com/businessfunctions/operations/our-insights/smart-cities-digital-solutions-for-a-more-livablefuture

11. Федеральная служба государственной статистики. Система национальных счетов [Электронный ресурс] Режим доступа: URL: https://gks.ru/bgd/free/b99_10/isswww.exe/stg/d000/i000310r.htm

12. Индекс человеческого развития / Human Development Index [Электронный ресурс] Режим доступа: URL: https://gtmarket.ru/ratings/humandevelopment-index

13. Gallup-Healthways Global Well-being Index [Электронный ресурс] Режим доступа: URL: http://info.healthways.com/hs-fs/hub/162029/file- 
1634508606-pdf/WBI2013/Gallup-Healthways_State_of_Global_WellBeing_vFINAL.pdf

14. Методология рейтинга EIU [Электронный ресурс] // The Economist Intelligence Unit's index of democracy. URL: http://www.economist.com/ media/pdf/DEMOCRACY_INDEX_2007_v3.pdf

15. Happy Planet Index [Электронный ресурс] Режим доступа: URL: http://happyplanetindex.org/

16. Hartig T. et al. Nature and health //Annual review of public health. 2014. - T. 35. - C. 207-228.

17. WHO Regional Office for Europe (2016) Urban green spaces and health. WHO Regional Office for Europe, Copenhagen URL: https://www. euro.who.int/_data/assets/pdf_file/0005/321971/Urban-green-spaces-and-healthreview-evidence.pdf

18. Braubach M. et al. Effects of urban green space on environmental health, equity and resilience //Nature-based solutions to climate change adaptation in urban areas. - Springer, Cham, 2017. - C. 187-205.

19. Всемирная организация здравоохранения. Европейское региональное бюро. Городские зеленые зоны: краткое руководство к действию URL: https://www.euro.who.int/_data/assets/pdf_file/0020/342290/Urban-GreenSpaces_RUS_WHO_web.pdf

20. Генеральная ассамблея ООН. Цели в области устойчивого развития [Электронный ресурс]. - Режим доступа: https://www.un.org/sustaina bledevelopment/ru/cities/

21. Larson L. R., Jennings V., Cloutier S. A. Public parks and wellbeing in urban areas of the United States //PLoS one. - 2016. - T. 11. - №. 4. - C. $\mathrm{e} 0153211$.

22. Boellstorff T. et al. For whom the ontology turns: Theorizing the digital real //Current Anthropology. - 2016. - T. 57. - №. 4. - C. 000-000. 
23. Your Maps - Режим доступа: URL: https://yourmaps.io/

24. Ahlfeldt G. Urbanity. CESifo working paper, No. 4533. Munich: Center for Economic Studies and Ifo Institute (CESifo) - 2013.

25. Есть такая профессия: цифровой антрополог. [Электронный ресурс].

- Режим доступа: https://strelkamag.com/ru/article/est-takaya-professiya-cifrovoiantropolog. 